\title{
Chromosome-level genome assembly of the Chinese Longsnout catfish Leiocassis longirostris
}

\author{
Wenping $\mathrm{He}^{1}$, Jian Zhou ${ }^{2}$, Zhe $\mathrm{Li}^{3}$, Tingseng $\mathrm{Jing}^{3}$, Chunhua Li ${ }^{4}$, Yuejing Yang ${ }^{3}$, Mengbin \\ Xiang ${ }^{3}$, Chaowei Zhou ${ }^{3}$, Guangjun $\mathrm{Lv}^{3}$, Hongyan $\mathrm{Xu}^{3}$, Hui Luo ${ }^{1}$, and Hua Ye ${ }^{1}$ \\ ${ }^{1}$ Key Laboratory of Freshwater Fish Reproduction and Development (Ministry of \\ Education) \\ ${ }^{2}$ Fisheries Institute of Sichuan Academy of Agricultural Science \\ ${ }^{3}$ Key Laboratory of Freshwater Fish Reproduction and Development (Ministry of \\ Education), College of Fisheries, Southwest University \\ ${ }^{4}$ BGI-Qingdao, BGI-Shenzhen
}

November 3, 2020

\begin{abstract}
The Chinese Longsnout catfish Leiocassis longirostris (L. longirostris) is one of the most economically important freshwater catfish in China. It is a valuable model for studies on sexual dimorphism, comparative and conservation biology since its wild resources have declined sharply. However, there is lack of high-quality chromosome-level genome information for comparative genomic analysis and genome evolutionary studies. Therefore, we constructed the first high-quality chromosome-level reference genome for L. longirostris using a combined strategy of BGI-SEQ500, Nanopore, and Hi-C technologies. The assembled genome of $\mathrm{L}$. longirostris contained a total length of $703.19 \mathrm{Mb}$ with 389 contigs, and an N50 size of 4.29 Mb. Using the Hi-C data, we finally successfully generated 82 chromosome-level scaffolds anchored onto 26 chromosomes with a total length of $685.53 \mathrm{Mb}$ (97.44\% of the total genome sequences), ranging in size from 17.36 Mb to $43.97 \mathrm{Mb}$. A total of 23,708 protein-coding genes were identified in the L. longirostris genome, and up to $97.73 \%$ of L. longirostris genes were functionally annotated. In addition, the genome contained $239.11 \mathrm{Mb}(33.99 \%$ in the total genome) repetitive sequences and 6,303 non-coding RNAs. The phylogenetic analysis indicated that the divergence time between L. longirostris and their closest relative species Pelteobagrus fulvidraco was approximately 26.6 million years. Collinearity analyses showed 26 chromosomes of L. longirostris displayed high homology with the corresponding scaffold ([?]3M) of P. fulvidraco and the corresponding chromosomes of the Ictalurus punctatus. The high-quality reference genome of L. longirostris was assembled for the first time and will pave a way for genome-scale selective breeding, genome comparisons and evolution investigations.
\end{abstract}

\section{Hosted file}

Chromosome-level genome assembly of the Chinese Longsnout catfish Leiocassis longirostris.pdf available at https://authorea.com/users/372614/articles/490572-chromosome-level-genomeassembly-of-the-chinese-longsnout-catfish-leiocassis-longirostris 


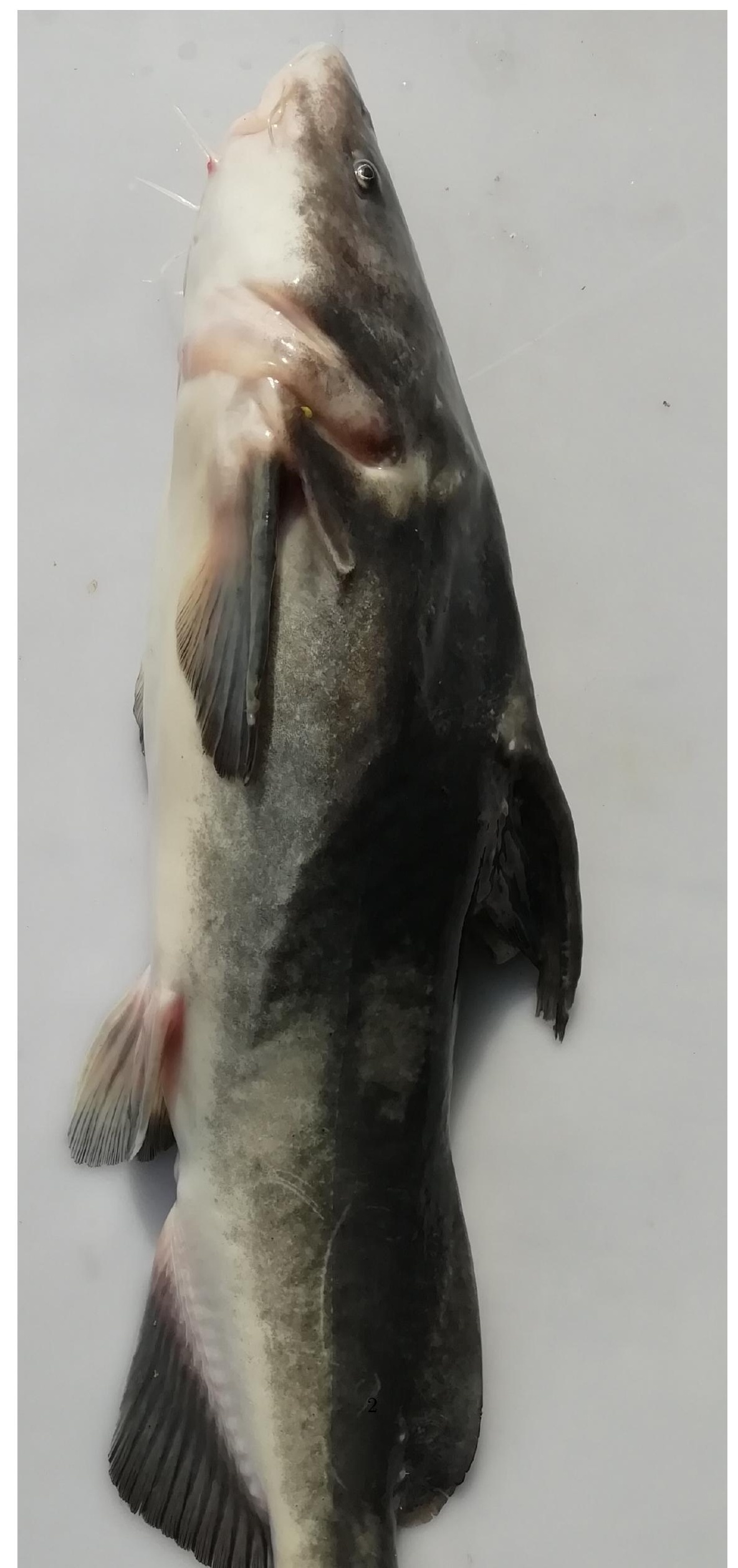




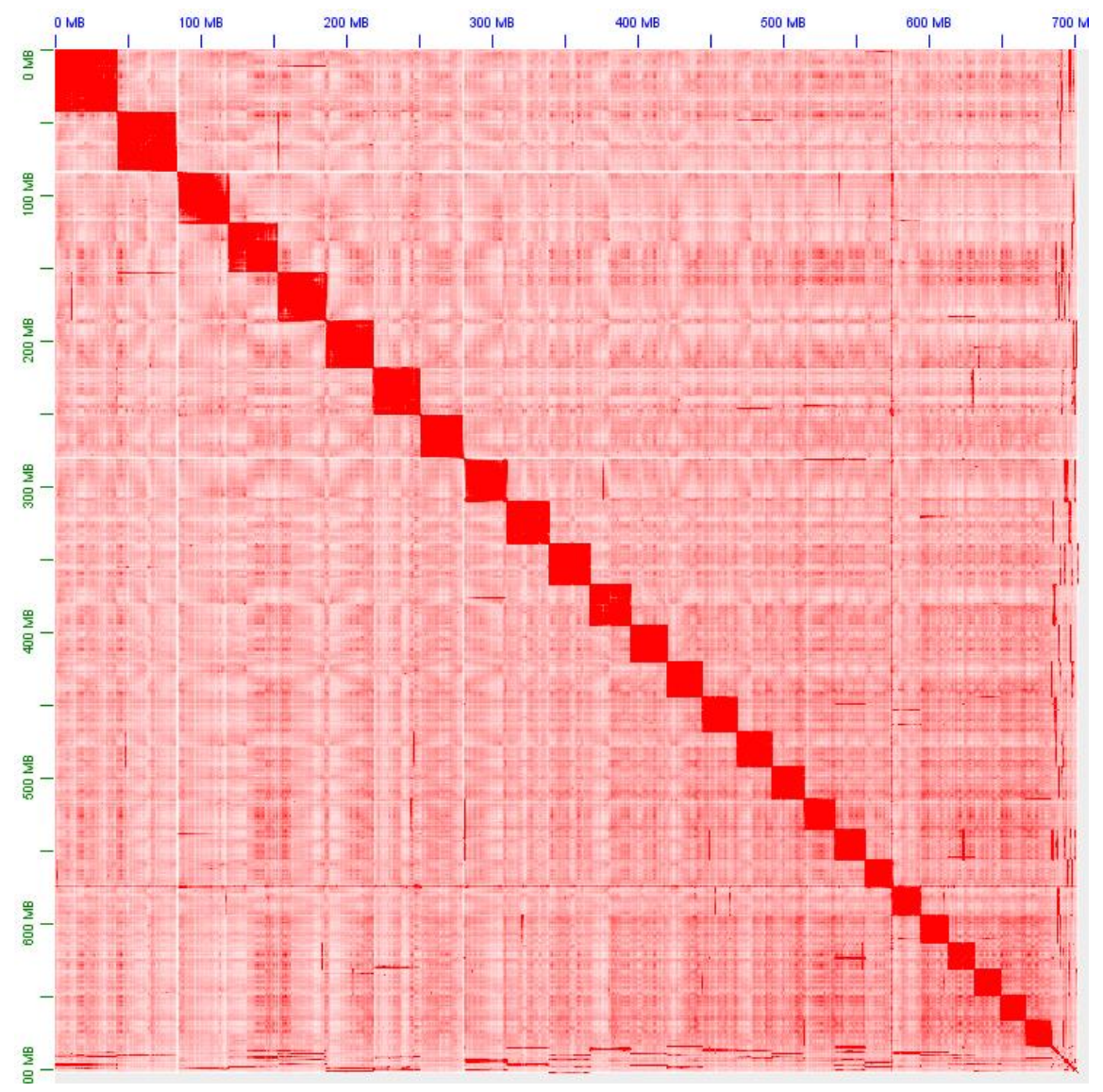




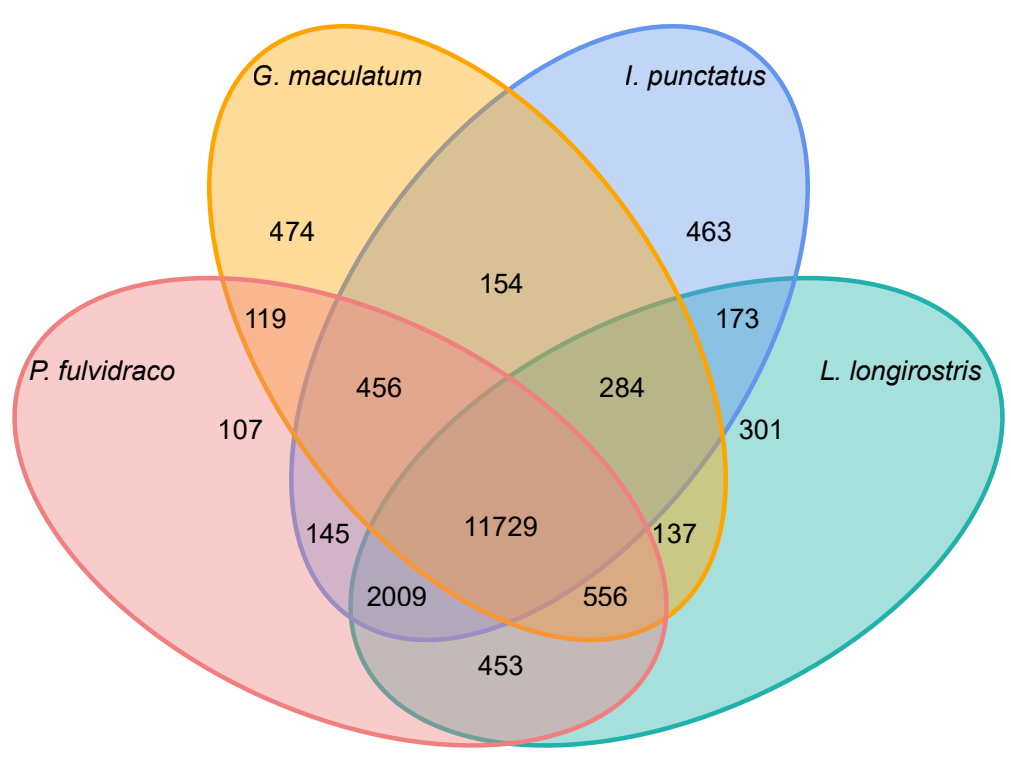

Number of gene families

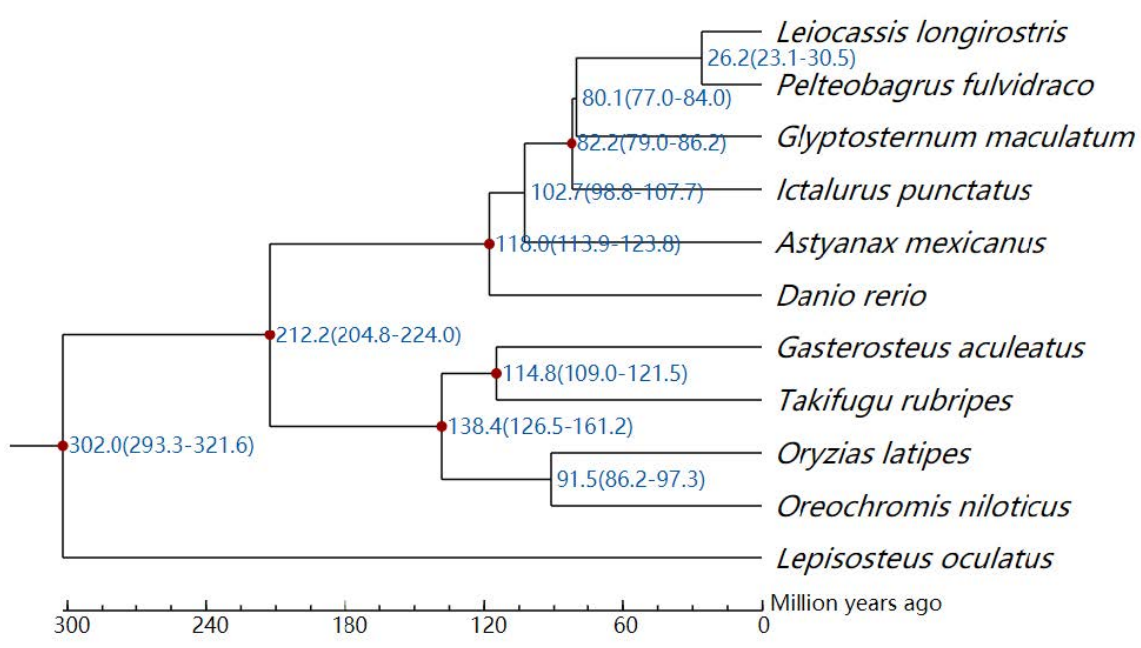



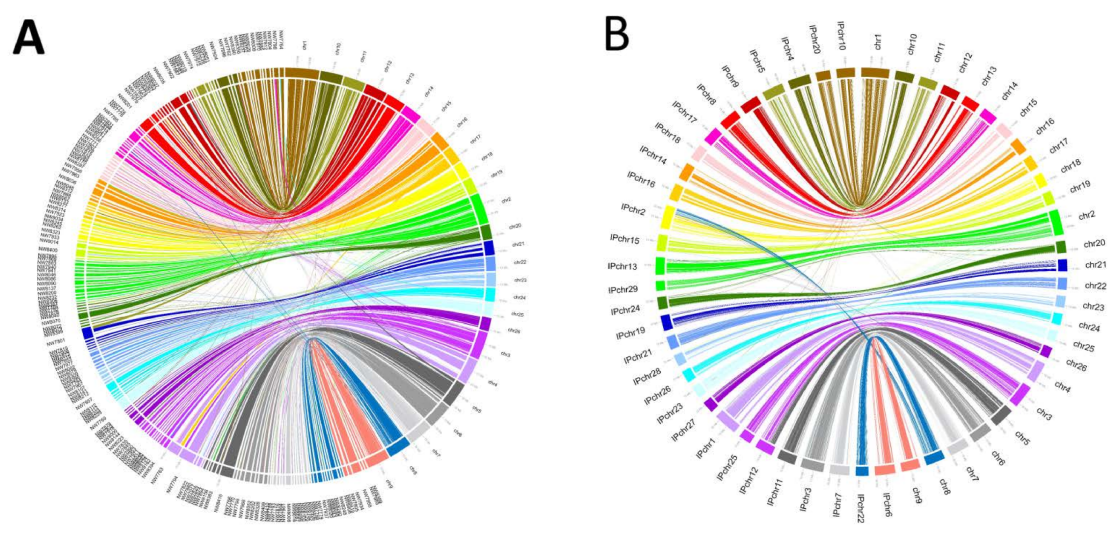